\title{
O CONTEXTO HISTÓRICO E O ESPAÇO REGIONAL EM VALSA PARA BRUNO STEIN, DE CHARLES KIEFER
}

\section{THE HISTORICAL CONTEXT AND THE REGIONAL SPACE IN VALSA PARA BRUNO STEIN, BY CHARLES KIEFER}

\author{
Cristiane da Silva Barcelos* \\ UCS
}

\section{Alessandra Paula Rech** \\ UCS}

Resumo: Este artigo analisa a função do contexto histórico e do espaço regional na obra Valsa para Bruno Stein, escrita pelo gaúcho Charles Kiefer. Para isso, aborda conceitos de região e trata do período histórico em que se passa a trama, na década de 1980, incluindo temas pincelados no texto, como a ditadura militar e o racismo. Autores como Pierre Bourdieu, Pedro Luis Barcia, José Clemente Pozenato, Flávio Loureiro Chaves e Terry Eagleton estão entre as referências consultadas neste estudo, que, ao final, explica a relevância da região na obra em questão.

Palavras chave: Região. História. Contexto histórico. Literatura

\begin{abstract}
This article analyses the function of the historical context and of the region in the book called Valsa para Bruno Stein, that was written by the South brazilian writer Charles Kiefer. This article addresses region concepts and studies the historical times that are showed on the book, as the eighties. It also shows another subjects as the military dictatorship that happened in Brazil and the racism. Authors as Pierre Bourdieu, Pedro Luis Barcia, José Clemente Pozenato, Flávio Loureiro Chaves and Terry Eagleton were studied for this article. The main objective is to say how much the region is relevant in the book.
\end{abstract}

Keywords: Region. History. Historical context. Literature

\section{Considerações iniciais}

Ao analisar a obra Valsa para Bruno Stein, escrita pelo gaúcho Charles Kiefer, este artigo se debruça sobre o pano de fundo histórico que é mostrado sutilmente ao longo da trama, bem como nos espaços evidenciados no livro. Com base em conceitos de região apresentados por autores como Pierre Bourdieu, Pedro Luis Barcia, José Clemente Pozenato, Flávio Loureiro Chaves e Terry Eagleton, pretende compreender a relevância dos espaços regionais bem como da contextualização histórica na obra em questão.

* Jornalista, mestre em Letras, Cultura e Regionalidade pela Universidade de Caxias do Sul (UCS), com bolsa Capes.

** Professora colaboradora do Mestrado em Letras e Cultura da Universidade de Caxias do Sul (UCS). Desenvolve estágio pós-doutoral no Programa Avançado de Cultura Contemporânea da UFRJ. Pesquisa, com apoio do CNPq, o programa Residência Criativa, do Instituto Hilda Hilst, em Campinas. 
O livro foi publicado originalmente em $1986^{1}$. O enredo gira em torno do personagem Bruno Stein, um oleiro de quase 70 anos de idade e extremamente conservador. Stein tenta manter a ordem da casa onde vive com a família de acordo com os costumes outrora ditados por ele, além de garantir a sobrevivência da olaria que funciona na propriedade. A trama se passa no Rio Grande do Sul, em uma cidade fictícia chamada Pau-d'Arco. O autor não cita diretamente o nome do estado do Rio Grande do Sul, mas, no decorrer do texto, apresenta informações que dão tal certeza ao leitor. Em alguns momentos, por exemplo, personagens falam do chimarrão, bebida conhecida como um dos símbolos dos gaúchos. Na passagem a seguir, a personagem Valéria oferece a bebida para o sogro, Bruno Stein: “Fiz chimarrão novo - disse Valéria, indicando-lhe a cuia no suporte assim que entrou na cozinha” (KIEFER, 2006, p. 24).

Embora a trama se passe em uma cidade inexistente no Rio Grande do Sul, o autor cita nomes de municípios verdadeiros como referência de lugares vizinhos, além de outros pontos conhecidos do Estado. Surgem no texto as cidades de Itaqui e Crissiumal, além da capital, Porto Alegre, bem como o Porto de Rio Grande. Esses e outros exemplos que evidenciam ao leitor onde se passa a trama são apresentados no decorrer da obra, na maior parte das vezes aparentemente sem pretensão de carregar um significado mais amplo, que não o de situar o leitor no espaço.

Kiefer também recorre a outros elementos para reforçar o lugar da trama. Um dos funcionários da olaria escutava a Rádio Guaíba (KIEFER, 2006, p. 126) - uma das mais tradicionais do Rio Grande do Sul -, e outro torcia para o Sport Club Internacional. "Passaria uma tinta branca na banda dos pneus, e, se pudesse, compraria ainda uma capa para o assento, do Sport Club Internacional, com a figura do negrinho sorridente” (KIEFER, 2006, p. 199), menciona o narrador ao escrever sobre o time do coração de outro funcionário da olaria, Gabriel, quando este comprou uma bicicleta.

Esses elementos, apresentados ao longo do livro em questão, podem ser apontados como aspectos indicativos de uma regionalidade, termo definido por José Clemente Pozenato como “todas as relações do fato literário com uma região” (2003, p. 155). A seguir, este artigo aborda o cenário histórico e social apresentado no decorrer do texto de Kiefer e reflete sobre a contribuição desses aspectos para o desenvolvimento do enredo.

\section{Pano de fundo histórico e contexto social}

O racismo e a repressão à mulher surgem nas páginas da obra, como temas secundários, em um cenário de despedida da ditadura militar. O racismo, por exemplo, já aparecia em uma frase anteriormente citada neste artigo, quando o narrador apresenta o personagem em sua obsessão pelo branco, da banda dos pneus ao assento da bicicleta de seu funcionário, onde
${ }^{1}$ Neste artigo é considerada a $8^{\text {a }}$ edição, publicada em 2006, pela editora Record. 
a figura do "negrinho sorridente" o perturba, numa referência à mascote do Internacional, o Saci. Um claro exemplo é o transcrito a seguir, que trata de um pensamento do protagonista em relação aos funcionários:

Um pouco antes do ranger dos gonzos, Bruno fizera algumas anotações nos livros de contabilidade, somara os adiantamentos de Erandi e Mário. O mulato, em apenas três semanas, consumira já o salário, precisava cortar-lhe o vale ou reduzi-lo ao mínimo. Questão de raça, concluía. Já Mário tinha no sangue o espírito de economia, pensava Bruno, o controle sobre si mesmo. Erandi, por sua vez, era desregrado, impertinente e arrogante. Não o despedia porque havia dez anos trabalhava na fábrica sem carteira assinada e, com frequência, entre uma frase e outra, o mulato fazia questão de lhe lembrar a existência do Ministério do Trabalho (KIEFER, 2006, p. 25).

Em artigo publicado na década de 1980, o antropólogo Roberto da Matta reflete sobre o racismo. No texto, intitulado Digressão: a fábula das três raças ou o problema do racismo à brasileira, da Matta aborda uma ideologia surgida em modo complexo, entre crises de abertura social: ele referia-se ao fato de no passado se libertar um escravo juridicamente, mas sem que ele passasse a ter condições de libertar-se social e cientificamente, além de perceber como o racismo foi "uma motivação poderosa para investigar a realidade brasileira” (DAMATTA, 1987, p. 69). Mais adiante, o antropólogo comenta:

No século XIX, entretanto, o racismo aparece na sua forma acabada, como um instrumento do imperialismo e como uma justificativa "natural" para a supremacia dos povos da Europa Ocidental sobre o resto do mundo. Foi esse tipo de "racismo" que a elite intelectual brasileira bebeu sofregamente, tomando-o como doutrina explicativa acabada para a realidade que existia no país (1987, p. 70).

Assim como as manifestações de alguns personagens caracterizam o racismo, outras apontam para o comportamento da mulher - e do homem em relação a ela. Enquanto o protagonista tenta manter o papel de patriarca, elas tomam a frente, seja a neta, que decide sair de casa sozinha por estar grávida, seja a nora, que passa a nutrir uma paixão pelo sogro. Aqui observa-se que, em relação aos direitos da mulher, os anos 1980 podiam ser considerados ainda embrionários no Brasil: o período conhecido como segunda onda feminista foi marcado entre as décadas de 1960 e 1980 e a criação de um Conselho Nacional dos Direitos da Mulher (CNDM)², responsável por fomentar ações, só ocorreria em 1985.

Também surgem na trama os apontamentos da descendência alemã dos principais personagens, o que remonta à colonização germânica no Rio Grande do Sul. Em um trecho, o protagonista, Bruno Stein, toma nas mãos a obra Fausto, do escritor alemão Johann Wolfgang von Goethe (KIEFER, 2006, p. 27) - aliás, frases retiradas desse livro surgem em epígrafes nos
${ }^{2} \mathrm{O}$ Conselho foi criado por meio da lei número 7.353, de 29 de agosto de 1985. 
três capítulos. Em diversas passagens de Valsa para Bruno Stein, a esposa de Bruno, Olga, expressa-se em alemão, como na transcrição a seguir:

- Mein Gott ${ }^{3}$ - exclamou Olga, irrompendo num choro convulso. Verônica levantou-se, contornou a mesa. Abraçou a avó por trás, beijou-a nos cabelos - Vens almoçar? - perguntou Olga de repente, ignorando a dor e as lágrimas - Vou fazer schnit'zel. ${ }^{4}$ [...] (KIEFER, 2006, p. 68, grifos originais).

Em ampla pesquisa a respeito da consolidação de alemães em terras gaúchas, Jean Roche aponta que o processo se deu em duas fases. A primeira delas ocorreu entre os anos de 1824 e 1889, período marcado pelo apontamento de São Leopoldo como berço da colonização (ROCHE, 1969, p. 94), e a segunda foi registrada a partir de 1889 (1969, p. 117). A pesquisa de Roche, publicada em 1969, já indicava a inexistência de colonos que falassem apenas o alemão, que havia deixado de ser uma língua exclusiva, embora continuasse sendo a preferida (1969, p. 655). No caso da obra de Kiefer, que é ficcional, a personagem Olga comunica-se em português, mas usa diversas expressões em alemão.

A escolha do sobrenome do personagem-título, aliás, é outro elemento que sinaliza para a ascendência dele. Segundo obra de Carlos H. Hunsche, o sobrenome em questão, "Stein”, figura na lista de imigrantes alemães que chegaram na então Colônia São Leopoldo ${ }^{5}$ entre 1824 e 1825 (1975).

A origem alemã e suas implicações, principalmente na personalidade do protagonista, também surgem na trama. Bruno Stein é um homem devoto da religião protestante, que comparece ao culto todos os domingos e que sempre reza antes de dormir, cita Clarissa Mombach em artigo escrito em 2012. No texto, Mombach destaca que os imigrantes que chegaram ao Brasil eram em geral protestantes ou católicos e que tiveram importante papel na vida religiosa brasileira. Segundo ela,

Kiefer faz uso dessa religiosidade alemã na construção da identidade de Bruno Stein; é através dos olhos da religião que este julgava a vida à sua volta: as pessoas, a televisão, o comportamento de cada um, o casamento, etc. O protagonista sempre se amparava na fé, crente de que essa lhe conferia a iluminação necessária para prosseguir, acreditando que as contradições do mundo e dos homens existiam para "testar os crentes, para prová-los até o limite de suas forças” (2012, p. 150).

Além da colônia alemã como pano de fundo, a obra dá indícios do período histórico em que se passa, ou seja, são elementos que auxiliam na compreensão e demarcam o tempo da trama: os anos 1980, mesma época em que o livro foi publicado. Um dos temas emergentes naquele período, a invasão de terras e a reforma agrária, é sinalizado quando é mencionada a distribuição de lotes feita pelo governo na Encruzilhada Natalino, região no entroncamento rodoviário próximo às cidades de Passo Fundo, Sarandi,

${ }^{3}$ Segundo Kiefer (2006), significa "meu Deus" em alemão.

${ }^{4}$ Conforme Kiefer (2006), em alemão significa bife malpassado, filé.

\author{
${ }^{5}$ Desde 2011, a \\ cidade de São \\ Leopoldo, na região \\ metropolitana \\ de Porto Alegre, \\ é oficialmente \\ considerada o berço \\ da colonização \\ alemã no Brasil. \\ Essa definição está \\ registrada na lei \\ federal $n^{0} 12.394$, de \\ 4 de março de 2011.
}


Carazinho e Ronda Alta, na região Norte do Rio Grande do Sul, durante o governo do então presidente João Baptista de Oliveira Figueiredo. O governo de Figueiredo, cujo mandato ocorreu de 1979 a 1985, também é citado na obra.

As dificuldades enfrentadas por Bruno Stein, cuja olaria tinha poucos funcionários, são apontadas e relacionadas com o período histórico. Bruno Stein mescla um drama pessoal, o de se interessar pela nora Valéria, com outro de ordem financeira, que era a dificuldade de manter o negócio. Em uma conversa com um interlocutor, que o questiona sobre o trabalho, Bruno Stein comenta que "[...] o dinheiro anda escasso, o concreto armado substituiu o tijolo” (KIEFER, 2006, p. 175). Esse contexto histórico também é sugerido com uma menção ao golpe militar:

Herman mexeu-se na cadeira, inquieto, coçou a barriga. O oleiro sentiu vontade de agredi-lo. Olga trouxe a cuia, a chaleira e um prato com biscoitos de polvilho. Preciso me controlar, Bruno pensou. Naquelas redondezas, todos odiavam Herman Hauser. Depois do golpe militar, à custa de subsídios para culturas inexistentes e empréstimos a juros baixos, fora acrescentando hectares e mais hectares à sua propriedade. Sempre que um colono se encontrava em condição de hipoteca, o gavião rondava a presa até conseguir comprar mais um naco para seu latifúndio [...] (KIEFER, 2006, p. 175).

Os elementos apresentados até aqui provocam uma reflexão sobre a ligação da história com a literatura, considerando que, em Valsa para Bruno Stein, essas características surgem de forma natural e discreta. Em uma análise geral sobre história e literatura, Flávio Loureiro Chaves aponta que não há uma fronteira entre as duas: “A fronteira, aqui, não se separa; antes, determina o ponto de convergência onde podemos observar a unidade da obra literária” (CHAVES, 1991, p. 9). Ainda sobre essa ideia de fronteira, Chaves cita Augusto Meyer:

Só a podemos entender fundindo texto e contexto numa interpretação dialeticamente íntegra, em que tanto o velho ponto de vista que explicava pelos fatores externos, quanto o outro, norteado pela conviç̧ão de que a estrutura é virtualmente independente, se combinam como momentos necessários do processo interpretativo (MEYER apud CHAVES, 1991, p. 9).

Na obra Leituras Cruzadas - diálogos da história com a literatura, Sandra Jatahy Pesavento analisa essas ligações quando menciona que o texto literário, ao ser utilizado como recurso para uma construção de conhecimento sobre o mundo, resgatando as sensibilidades de uma época determinada, "poderá dar indícios dos sentimentos, das emoções, das maneiras de falar, dos códigos de conduta partilhados, da gestualidade e das ações sociais de outro tempo (PESAVENTO, 2000, p. 8). 
Para fazer uma reflexão sobre essa ligação entre história e literatura, Chaves utiliza como exemplo obras de José de Alencar (1829 - 1877). Chaves explica que Alencar definiu três fases da literatura nacional, quais sejam: a primitiva (aquela acerca de mitos e lendas, entre as quais estava Iracema); a histórica (que representava o contato do povo invasor com o espaço brasileiro, citando como exemplos O Guarani e As Minas de Prata), e, por fim, uma etapa até então em desenvolvimento, que trataria de valorizar "a cor local” e o resgate do passado - para essa última, os exemplos são $O$ tronco de ipê, Til e $O$ Gaúcho. Na visão de Chaves, essas definições caminhavam junto não apenas com um amadurecimento intelectual do autor citado como exemplo, mas também de um projeto “com vistas à aquisição da identidade nacional e sua expressão literária” (1991, p. 16).

Para Chaves, Alencar “provocou a confluência entre a História e a Literatura, justamente no território da ficção”, e desta forma, “traçou em linha reta o objetivo final do romance histórico, recém-nascido e já acionado subterraneamente pela força poderosa da ideologia” (1991, p. 18, grifo original). $\mathrm{O}$ autor entende que

talvez possamos nos distanciar então daqueles romances declaradamente atrelados à crônica histórica, para lermos num outro lugar uma outra História; a História que, sem ser rotulada como tal, pode ser inferida do texto de ficção, até inaugurando a medida contra-ideológica (sic) da primeira (CHAVES, 1991, p. 19, grifo original).

Essa linha de raciocínio tomada por Chaves, em que o contexto histórico não é protagonista da obra mas surge no decorrer do texto, pode servir como avaliação do livro em questão, Valsa para Bruno Stein, de Charles Kiefer. Enquanto a trama corre tendo como figura central um personagem e não um período histórico, os fatos que permeiam aquela época surgem aos poucos, levando o leitor a navegar em um certo intervalo de tempo.

O cenário histórico de Valsa para Bruno Stein, a década de 1980, se mostra em paralelo com o desenrolar da trama envolvendo os personagens principais. Trata-se de uma época em que o Brasil começava a se desfazer de um período de forte repressão, o da ditadura militar, compreendida entre 1964 e 1985. Em extensa obra sobre a ditadura, Ronaldo Costa Couto dá uma ideia do que se passava na metade da década de 1980, quando, em 1985, o país empossava o primeiro presidente - mesmo que de forma indireta - após os anos dominados pelo regime militar:

A travessia está concluída. A transição se completou. Não foi apenas o governo que mudou, mas o regime político. O Brasil já é, de fato e de direito, uma democracia política. A maior prioridade agora é consolidar a transição. Remover a legislação autoritária remanescente, institucionalizar o estado de direito, escrever nova carta política por intermédio de assembleia nacional constituinte livre e soberana. É o que acontece. A democracia se consolida rapidamente, livre da tutela militar, estável e talvez irreversível (2003, p. 443). 
A propriedade do homem que dá título ao livro, Bruno Stein, remete aos minifúndios alemães no Rio Grande do Sul. Na trama é citada a Pastoral da Terra (KIEFER, 2006, p. 214), criada pela Igreja Católica em junho de 1975 para desenvolver o trabalho no campo. Dessa forma, era quebrado o monopólio de poder por parte dos maiores proprietários de cada região (KUCINSKI, 2001, p. 112). Nessa época, mas um pouco antes de grandes greves operárias que marcaram a segunda metade da ditadura militar, se iniciava uma luta de certa forma silenciosa, de parte de posseiros de terra, que não dispunham de títulos legais de posse de seus territórios, e de grandes fazendeiros ou grupos econômicos, que tentavam se apossar desses locais valendo-se de documentos nem sempre legítimos (KUCINSKI, 2001, p. 113). Na obra de Kiefer, essa realidade é abordada quando o autor cita que colonos sem-terra haviam acampado dentro do limite pertencente a Bruno Stein (KIEFER, 2006, p. 212).

A questão, no entanto, não é debater o que é verdade ou ficção na obra literária em análise, mas buscar compreender a relevância da realidade (leia-se, o contexto histórico) no desenrolar da trama. É o que defende, por exemplo, Terry Eagleton: “a distinção entre ‘fato’ e ‘ficção’, portanto, não parece nos ser muito útil, e uma das razões para isso é que a própria distinção é muitas vezes questionável” (EAGLETON, 2006, p. 2). Eagleton remonta a um exemplo britânico para esclarecer a linha de raciocínio:

No inglês de fins do século XVI e princípios do século XVII, a palavra "novel” foi usada, ao que parece, tanto para os acontecimentos reais quanto para os fictícios, sendo que até mesmo as notícias de jornal dificilmente poderiam ser consideradas fatuais. Os romances e as notícias não eram claramente fatuais, nem claramente fictícios, a distinção que fazemos entre estas categorias simplesmente não era aplicada [...]. Além disso, se a "literatura" inclui muito da escrita "fatual”, também exclui uma boa margem de ficção (2006, p. 2).

O fato de Valsa para Bruno Stein estar alicerçada em um determinado contexto histórico pode ter relevância maior ou menor de acordo com quem for o leitor. Explicamos, com base em argumento defendido por Eagleton: "A definição de literatura fica dependendo da maneira pela qual alguém resolve ler, e não da natureza daquilo que é lido” (2006, p. 12).

Eagleton salienta que, de acordo com cada leitor, "todas as obras literárias “são 'reescritas', mesmo que inconscientemente, pelas sociedades que as leem” (2006, p. 19):

O fato de sempre interpretarmos as obras literárias, até certo ponto, à luz de nossos próprios interesses - e o fato de, na verdade, sermos incapazes de, num certo sentido, interpretá-las de outra maneira - poderia ser uma das razões pelas quais certas obras literárias parecem conservar seu valor através dos séculos. Pode acontecer, é claro, que ainda conservemos 
muitas das preocupações inerentes à da [sic] própria obra, mas pode ocorrer também que não estejamos valorizando exatamente a "mesma obra". O "nosso" Homero não é igual ao Homero da Idade Média, nem o "nosso" Shakespeare é igual ao dos contemporâneos desse autor (2006, p. 18).

Assim, Eagleton defende a ideia de uma literatura definível pela linguagem que emprega e não pelo fato de ela ser ficcional ou não. Quanto a Valsa para Bruno Stein, trata-se de um livro que conta com o fator histórico como uma espécie de base em que se desenvolve toda a trama, mostrado de forma sutil e sem de forma alguma "engessar" o desenrolar dos acontecimentos. Em outras palavras, na obra analisada o contexto histórico funciona muito mais como um suporte que explica a conduta de certos personagens, como o perfil conservador do protagonista Bruno Stein, reforçado pela época, e o aspecto do comportamento das mulheres, que começam a buscar autonomia em uma sociedade conservadora.

\section{A relevância do espaço}

Embora indique traços que situem o leitor no lugar onde ocorre a trama, ou seja, o Rio Grande do Sul, Valsa para Bruno Stein não pode ser entendido, a partir do recurso analisado, como um livro de características regionalistas. Essa posição surge com base em autores como Pedro Luis Barcia, que defendem a literatura regionalista como aquela que resulta em algum tipo de exaltação da região - o que não é percebido em Valsa para Bruno Stein. Barcia argumenta:

O regionalismo literário ou a literatura regionalista supõe um grau de exasperação, um acentuar do regional. Este pedal de apoio "ismo" pode chegar à hipertrofia. A literatura regionalista é produto de um profissionalismo da regional. O regionalismo gera uma literatura "regionalizada” por decisão do autor, limitada à região, centrada nela (2004, p. 39, tradução nossa). ${ }^{6}$

Para prosseguir com a análise da relevância da região na obra, necessita-se, logicamente, revisitar conceitos. As considerações do francês Pierre Bourdieu podem servir como caminho inicial para definir uma região. Para o autor,

[...] a região é o que está em jogo como objeto de lutas entre os cientistas, não só geógrafos, é claro, que, por terem que ver com o espaço, aspiram ao monopólio da definição legítima, mas também historiadores, etnólogos e, sobretudo desde que existe uma política de "regionalização" e movimentos “regionalistas”, economistas e sociólogos (2003, p. 108).

Bourdieu acrescenta: “[...] dá-se igualmente demasiada importância aos fenômenos físicos, como se o Estado não interviesse, como se os movimentos de capitais ou as decisões dos grupos não produzissem efeitos” (2003, p. 108).
${ }^{6}$ Do original:

El regionalismo literario o la literatura regionalista suponen un grado de exasperación, un acentuar, por el sufijo, lo regional. Este apoyar el pedal del “ismo” puede llegar a la hipertrofia. La literatura regionalista es producto de un profesionalismo de lo regional. El regionalismo genera una literatura "regionalizada" por decisión del autor, limitada a la región, centrada en ella (BARCIA, 2004, p. 39). 
Com relação ao regionalismo, Bordieu tem linha de raciocínio que fora perseguida por Barcia, ou seja, defende que o discurso regionalista é performativo e que busca tornar legítima uma nova definição de fronteiras e assim determinar a região (BOURDIEU, 2003). O autor entende ainda que “a reivindicação regionalista, por muito longínqua que pareça desse nacionalismo sem território, é também uma resposta à estigmatização que produz o território de que, aparentemente, ela é produto” (BOURDIEU, 2003, p. 126). Assim, tanto as ideias de Barcia como as de Bourdieu convergem para uma interpretação comum, a de que Valsa para Bruno Stein nada tem de regionalista.

Em Valsa para Bruno Stein, em que as paisagens são raramente descritas e não há uma preocupação em destacar ou pormenorizar fortemente o lugar, o espaço regional parece surgir como um elemento complementar, responsável por cumprir a obrigação de levar o leitor a algum lugar durante a leitura. Esse espaço, portanto, não demonstra ser determinante para o desenrolar da história: o destino traçado pelo autor para os personagens parece ter muito mais a ver com as transformações internas que sofrem no decorrer da trama do que explicitamente com o lugar em que vivem.

Em 2003, quando da publicação de Processos Culturais: reflexões sobre a dinâmica cultural, José Clemente Pozenato explicava que, em 20 anos (compreendidos desde o início de seus estudos a respeito de região), mudara a direção em que o tema era abordado. Para simplificar a argumentação, Pozenato explica que a conceituação variara de uma visão negativa para uma positiva. $\mathrm{O}$ autor descreve: as relações regionais passaram a ser vistas como "um modo adequado de entender como funciona, ou pode funcionar, o processo de mundialização de todas as relações humanas”, enquanto, antes, o regionalismo era tido tão somente como "uma visão estreita do processo social” (POZENATO, 2003, p. 149).

Pozenato defende a região não como uma realidade natural, mas “uma divisão do mundo social estabelecida por um ato de vontade”, que, para ele, não é arbitrária. O autor defende que a região, "sem deixar de ser em algum grau um espaço natural, com fronteiras naturais, é antes de tudo um espaço construído por decisão, seja política, seja da ordem das representações, entre as quais as de diferentes ciências” (POZENATO, 2003, p. 150, grifos originais).

Ao se referir à região como um espaço natural, Pozenato destaca que essa ideia teria surgido a partir da geografia física, mas pondera que é possível tratar de "região histórica, região cultural, região econômica e assim por diante, com fronteiras distintas no mesmo território físico” (2003, p. 150).

Para Pozenato, tanto o conceito de região quanto a definição de uma determinada região são construções, ou seja, trata-se de representações simbólicas (2003, p. 151). Para sustentar essa linha de raciocínio, o autor remete à física quântica, ciência que prega que "só existe como fenômeno 
aquilo que conseguimos construir na nossa linguagem” (2003, p. 151). Assim, ele defende a região como uma espécie de rede de relações que são utilizadas para defini-la. O estudioso recorre à seguinte explicação para deixar a teoria ainda mais clara:

Uma determinada região é constituída, portanto, de acordo com o tipo, o número e a extensão das relações adotadas para defini-la. Assim, em última instância, não existe uma região da Serra ou uma região da Campanha a não ser em sentido simbólico, na medida em que seja construído (pela práxis ou pelo conhecimento) um conjunto de relações que apontem para esse significado. Isto é, o que é entendido como uma região é, realmente, uma regionalidade. Não vejo no entanto problema em continuar falando em região, contanto que por tal não fique entendida uma realidade natural, mas uma rede de relações, em última instância, estabelecida por um autor, seja ele um cientista, um governo, uma coletividade, uma instituição ou um líder separatista (2003, p. 152, grifo original).

Paul Bois (1960) é citado por Pozenato para ligar a história com a região. Pozenato levanta a discussão a respeito do que constitui a região se o espaço ou o tempo (a história) - e destaca que, para Bois, sem dúvida é a história. Pozenato esclarece, dizendo que se a região representa um espaço, ela é na verdade um espaço que foi definido por uma história diferente daquela de um outro espaço, vizinho e externo (2003, p. 152). Assim, destaca a relevância de se levar em consideração aspectos sociais (como a história), e não apenas os de ordem física ou de paisagem, na concepção de uma região. Pozenato reforça: “a região será melhor entendida se vista como simplesmente um feixe de relações a partir do qual se estabelecem outras relações, tanto de proximidade como de distância (2003, p. 157).

Essa ideia de feixe de relações também pode ser aplicada para compreender o sentido da região em Valsa para Bruno Stein: como argumentado até aqui, não se trata de uma obra regionalista, mas que se cerca de dados que indicam a uma determinada região, entrelaçados com pinceladas históricas. Enfim, o feixe de relações seria formado pela história, pelo lugar em que a trama se passa, no interior do Rio Grande do Sul, e pelas singularidades de cada personagem.

Em Valsa para Bruno Stein, o espaço regional surge como um elemento complementar. Esse espaço, portanto, não demonstra ser determinante para o desenrolar da história: o destino traçado pelo autor para os personagens não mostra ligação direta com o lugar em que vivem, mas sim com as transformações internas que sofrem durante a trama, todas de alguma forma ligadas às influências culturais da região e ao contexto histórico-político.

É o que ocorre, por exemplo, com o protagonista. Stein é um homem idoso, com ideias fixas, avesso a certas "modernidades”, como a televisão, que para ele servia para corromper as pessoas, como demonstra esta fala do personagem na primeira parte do livro: “É por causa dessas novelas indecentes 
que as meninas perderam o respeito pelos mais velhos” (KIEFER, 2006, p. 31). Porém, é ao perceber-se atraído pela nora, Valéria, que o homem passa a vivenciar uma revolução interna, que nada tem a ver com o fato de ele morar em uma fazenda no interior do Rio Grande do Sul. Ou seja, o que se torna evidente é a mudança de opinião de Stein, que acaba concretizando o amor com a nora, e a quebra de paradigmas de comportamento, como se permitir sentar em frente à televisão e prestar atenção à tela, ato pelo qual sempre sentira verdadeiro asco.

Outro aspecto a observar é a escolha do nome da cidade em que se passa a trama, Pau-d'Arco, que pode ter sido uma referência à obra de Corpo de Baile (Guimarães Rosa, 1965). Pau-d’Arco equivale ao Ipê, árvore bastante comum em solo gaúcho, mas Kiefer pode ter ido além, já que a planta pode estar ligada a uma ideia de crescimento ou de superação, se tomado por base um exemplo usado por Guimarães Rosa: em A Estória de Lélio e Lina, um dos contos da referida obra, o personagem Lélio encontra um pé de pau-d'arco e o marca para transformá-lo em uma vara quando estiver em ponto de corte. Depois, Lélio reencontra o arbusto marcado, o que, para Rech (2010), pode fazer referência a “[...] seu próprio crescimento, sua virilidade em maturação” (2010, p. 48).

Neste sentido, Kiefer pode ter recorrido a esse termo para nomear sua cidade imaginária em uma possível relação com a trajetória de crescimento interno do protagonista, que vive os anseios de se descobrir apaixonado pela nora e tem os seus costumes conservadores desafiados, principalmente pela neta Verônica. Outro indicativo de que Kiefer possa ter buscado referências na obra de Rosa é que, em Buriti, outro dos contos de Corpo de Baile, Rosa tratava sobre o amor entre nora e sogro, justamente o que Kiefer abordou em Valsa.

\section{Considerações finais}

Ao criar uma cidade fictícia no Rio Grande do Sul mas ao mesmo tempo mencionar pontos verdadeiros como referência geográfica, Kiefer consegue situar a obra em um determinado espaço, sem no entanto ligar a trama diretamente ao lugar ou torná-la dependente da região, ou seja, mantendo a autonomia da proposta ficcional. Assim, o autor apresenta aspectos da cultura gaúcha ao mesmo tempo em que deixa clara a ascendência alemã dos Stein, marcada principalmente pelo modo de falar da esposa do protagonista. Esses aspectos são demonstrados sem que o autor aposte em clichês ou peque pelo exagero, como é comum em muitos casos em que escritores tentam retratar características dos gaúchos - o fato de Kiefer ser do Rio Grande do Sul certamente contribui para o modelo de abordagem adotado.

Por outro lado, o período histórico escolhido por Kiefer para servir de pano de fundo para a trama dá relevância à obra. O livro foi publicado 
originalmente em 1986, apenas um ano depois do fim da ditadura militar, ou seja, quando as tensões vividas ainda se faziam presentes no cotidiano dos brasileiros - e provavelmente nas ideias do autor. A temática da repressão está presente, embora abordada de forma secundária, e Kiefer consegue entrecruzar esse aspecto demarcado no tempo com outros que tornam o enredo completamente atual. Como exemplo disso, pode ser citada a submissão e a libertação feminina, representadas respectivamente pelas personagens Olga (esposa de Bruno Stein) e pela neta, Verônica.

Assim, observa-se a região e os fatores históricos como elementos que, de forma intrínseca, atuam na formação dos personagens e, também de forma intrínseca, fazem parte do processo de transformação de cada um deles. Um exemplo claro é o fato de Bruno Stein se render à televisão ao final da obra: essa passagem torna-se uma grande surpresa justamente por ele ser um homem ligado à vida no campo e avesso a qualquer modernidade que ousasse invadir seu território. Logo, o contexto histórico e social integra o processo evolutivo dos personagens. Trata-se de um conjunto de fatores em que a região também atua, mas não parece ser determinante para direcionar a trama, uma vez que, sob um prisma longitudinal, o que conta são questões humanas que transcendem o momento e a paisagem, possibilitando identificação para o leitor inserido em tempos e contextos diversos.

\section{Referências}

A luta do Acampamento Encruzilhada Natalino. Movimento dos Trabalhadores Rurais Sem Terra, 2001. Disponível em:<http://www.mst. org.br/2014/06/18/a-luta-do-acampamento-encruzilhada-natalino.html>. Acesso em: 20 jun. 2018.

BARCIA, Pedro Luis. Hacia un concepto de la literatura regional. In: CASTELLINO, Marta Elena; RIVERO, Gloria Videla de (Orgs). Literatura de las regiones argentinas. Mendoza: Universidad Nacional Del Cuyo, 2004.

BOURDIEU, Pierre. O poder simbólico. Rio de Janeiro: Bertrand Brasil, 2003.

CHAVES, Flávio Loureiro. História e literatura. Porto Alegre: Editora da Universidade Federal do Rio Grande Sul, 1991.

COUTO, Ronaldo Costa. História indiscreta da ditadura e da abertura. Brasil: 1964-1985. Rio de Janeiro: Record, 2003.

DAMATTA, Roberto. Relativizando: Uma introdução à antropologia social. Rio de Janeiro: Rocco, 1987.

EAGLETON, Terry. Teoria da literatura: uma introdução. São Paulo: M. Fontes, 2006. 
HUNSCHE, Carlos H. O biênio 1824/25 da imigração e colonização alemã no Rio Grande do Sul (Província de São Pedro). Porto Alegre: A Nação, 1975.

KIEFER, Charles. Valsa para Bruno Stein. Rio de Janeiro: Record, 2006.

KUCINSKI, Bernardo. O fim da ditadura militar. São Paulo: Contexto, 2001.

MOMBACH, Clarissa. Um fausto brasileiro? Uma análise intertextual de Valsa para Bruno Stein. Literatura em Debate. Porto Alegre, v. 6, n. 11, p. 139-153, dez. 2012.

PESAVENTO, Sandra Jatahy (org). Leituras Cruzadas: diálogos da história com a literatura. Porto Alegre: Editora da Universidade Federal do Rio Grande do Sul, 2000.

POZENATO, José Clemente. Processos culturais - reflexões sobre a dinâmica cultural. Caxias do Sul: Educs, 2003.

RECH, Alessandra. Na entrada-das-águas: amor e liberdade em Guimarães Rosa. Caxias do Sul: Educs, 2010.

ROCHE, Jean. A colonização alemã e o Rio Grande do Sul. Porto Alegre: Globo, 1969. 2 v

Recebido em agosto/2018.

Aceito em dezembro/2018. 